\title{
Influence of irregularity of water consumption on water age in a water supply network
}

\author{
Ewa Ogiołda ${ }^{1, *}$, and Ireneusz Nowogoński ${ }^{1}$ \\ ${ }^{1}$ University of Zielona Góra, Faculty of Civil Engineering, Architectural and Environmental \\ Engineering, 65-417 Zielona Góra, Poland
}

\begin{abstract}
The article presents an analysis of an existing water supply system. Water consumption in various time frames, i.e. a year, week and 24 hours, is shown. A hydraulic model was developed and, using the EPANET programme, calculations simulating its parameters carried out, accounting particularly for water age, which reflective of the water quality supplied to the recipients. The obtained results are the basis for assessing the operation of the system.
\end{abstract}

\section{Introduction}

The basis for dimensioning water supply systems is the demand for water which, over the course of their use, may undergo changes, thus resulting in changes in their operating parameters. Relationships occur between hydraulic parameters of the network, the construction of pipelines and the construction of individual structures, as well as the quality of water supplied to the recipients. The system is to supply sufficient amounts of water, under adequate pressure and of proper quality to the recipients, and thus prevent the occurrence of secondary water contamination [1].

Parameters characterizing water consumption can be analysed in different time frames. Factors influencing the irregularity of water consumption are varied; they may include, e.g., the recipients' lifestyles, habits, or the organisation of their work time, as well as meteorological factors [2].

Computer programmes make it possible to develop simulation models and carry out calculations of many system parameters, both hydrological as well as characterizing the quality of water. Among the programmes used for this purpose is EPANET [3].

The obtained results are the basis for making decisions regarding operational activities as well as the modernization of existing and planned systems.

\section{Study area characteristics}

The analysed water supply network is in the city of Babimost, located in the central-eastern part of the Lubuskie Province, and supplies 4,040 inhabitants. The water supply network is supplied from an underground water intake, which comprises two drilled wells.

\footnotetext{
* Corresponding author: e. ogiolda@,iis.uz.zgora.pl
} 
Submersible pumps of GC.5.03 type manufactured by HYDROVACUUM in Grudziądz are used in the alternately operating wells. Following aeration and filtration processes, water finds its way to a tank, from where it is pumped to the network by 4 pumps of the 65WR40-2/2 type, produced by LFP Leszno ( 3 operating pumps and 1 back-up pump). Elevation within the area of supply ranges from 55.5 to 61.1 ma.s.l.

The water supply network of the city of Babimost was constructed in the years 2000-2005. It forms a mixed system, comprising 17 closed circuits. The total length of the network is $22.9 \mathrm{~km}$. The pipelines are made of different materials, i.e.:

- $\operatorname{PVC} \varphi 225-4.0 \mathrm{~km}, \varphi 160-3.8 \mathrm{~km}, \varphi 110-7.3 \mathrm{~km}$,

- PE $\varphi 90-2.4 \mathrm{~km}, \varphi 63-1.3 \mathrm{~km}$,

- cast iron $\varphi 90-4.1 \mathrm{~km}$.

Water in Babimost is used for residential needs as well as for commercial and industrial purposes.

\section{Methodology}

Calculations of the water supply network in Babimost were carried out using the EPANET programme made available by the Water Supply and Water Resources Division of the U.S. Environmental Protection Agency.

The EPANET programme is intended for hydraulic computer simulations as well as the analysis of water flows in pressure networks. It is applied for the analysis of water flows in water supply networks, making it possible to carry out the calculations of numerous parameters, including: water pressure in nodes, flow rate in individual segments, water age, energy consumption, and the concentration of chemical compounds [3].

The starting point for calculations is designing a graph of the network and introducing data characterizing individual elements of the system: segments of the network (length, diameters and roughness), nodes of the network (amount and pattern of water consumption, elevations), number of pumps and pump orienting points, and the ordinates of the water surface in reservoirs.

The graph of the water supply network in Babimost presented in Figure 1 consists of 78 nodes 98 pipelines, a reservoir and 4 pumps [4].

The EPANET programme makes it possible to choose the method of calculating pressure loss from the following formulas: Darcy-Weisbach, Hazen-Williams, and ChezyManning. The Darcy-Weisbach [3] formula was selected for carrying out calculations [5]:

$$
\Delta h=\lambda \frac{l}{d} \frac{v^{2}}{2 g}
$$

where:

$\Delta h$ - pressure loss in segment, $\mathrm{m}$,

$\lambda$ - linear roughness coefficient,

$l$ - length of pipeline, $\mathrm{m}$,

$d$ - inside diameter of pipeline, $\mathrm{m}$,

$v$ - average flow rate, $\mathrm{m} \cdot \mathrm{s}^{-1}$,

$g$ - gravitational acceleration, $\mathrm{m} \cdot \mathrm{s}^{-2}$. 


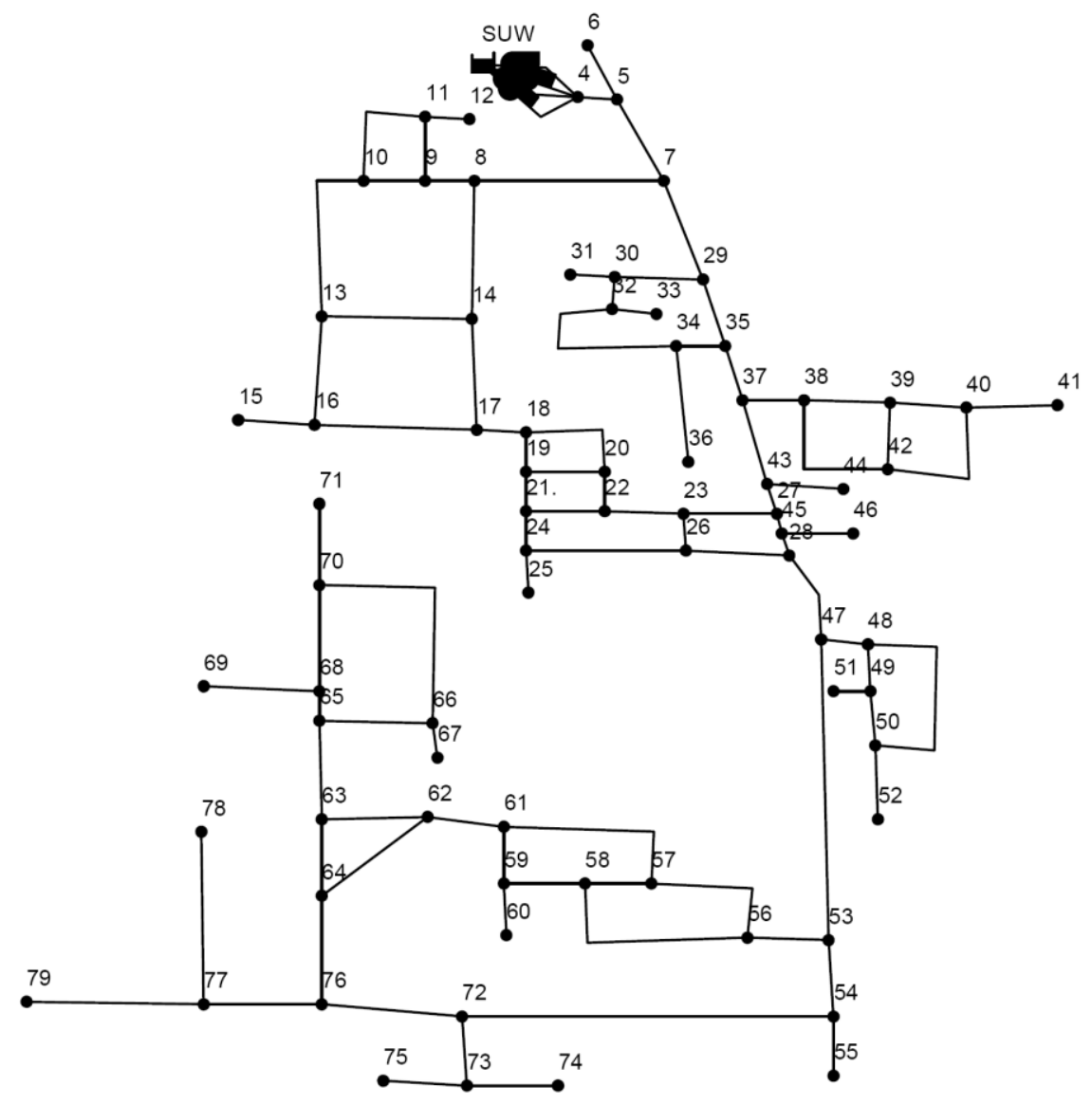

Fig. 1. Graph of the water supply system in Babimost [4].

The full hydraulic calibration wasn't carried out, whereas macro-level calibration has been done - results of pressure calculation have been compared with measured values in two remote nodes during water consumption conditions corresponding to maximum values. They haven't differed more than $3 \mathrm{~m}$, what was found acceptable.

In order to calculate individual parameters in subsequent hours, a pattern characterizing the irregularity of water consumption over the course of a 24-hour period is necessary. It contains coefficients calculated for every hour according to the following formula:

$$
P=\frac{Q_{h i}}{Q_{h \max }}
$$

where:

$Q_{h i}$ - water consumption in $i$-th hour of day (24-hour period), $\mathrm{m}^{3} \cdot \mathrm{h}^{-1}$, $Q_{h \text { max }}$ - maximum water consumption over the course of a 24 -hour period, $\mathrm{m}^{3} \cdot \mathrm{h}^{-1}$. 
The EPANET programme calculates the values of water age for each hour of the simulation for individual segments and nodes. It is on their basis that the weighted average water age characterizing pipelines of a given diameter is determined [6]:

$$
W=\frac{\sum_{i=1}^{n}\left(W_{i} \cdot L_{i}\right)}{L}
$$

where:

$W_{i}$ - water age calculated for all pipelines of a given diameter $d, \mathrm{~h}$,

$L_{i}-$ length of all pipelines of a given diameter $d, \mathrm{~m}$,

$L-$ sum of lengths of all pipelines, $\mathrm{m}$.

\section{Results of calculations}

\subsection{Irregularity of water consumption}

Calculations were carried out for water consumption in Babimost in the years 2014-2016. Irregularity of water consumption can be analysed in different time frames, e.g., over the course of a year, week or day.

The values of water consumption are presented in Fig. 2 in individual months of the analysed time period. A decrease in water consumption in subsequent years is seen (lowest values in the year 2016), which confirms the tendencies observed in other systems [2]. Characteristic of the system in Babimost is the highest water consumption in summer months (July, August). Such variation results from the effects of meteorological conditions.

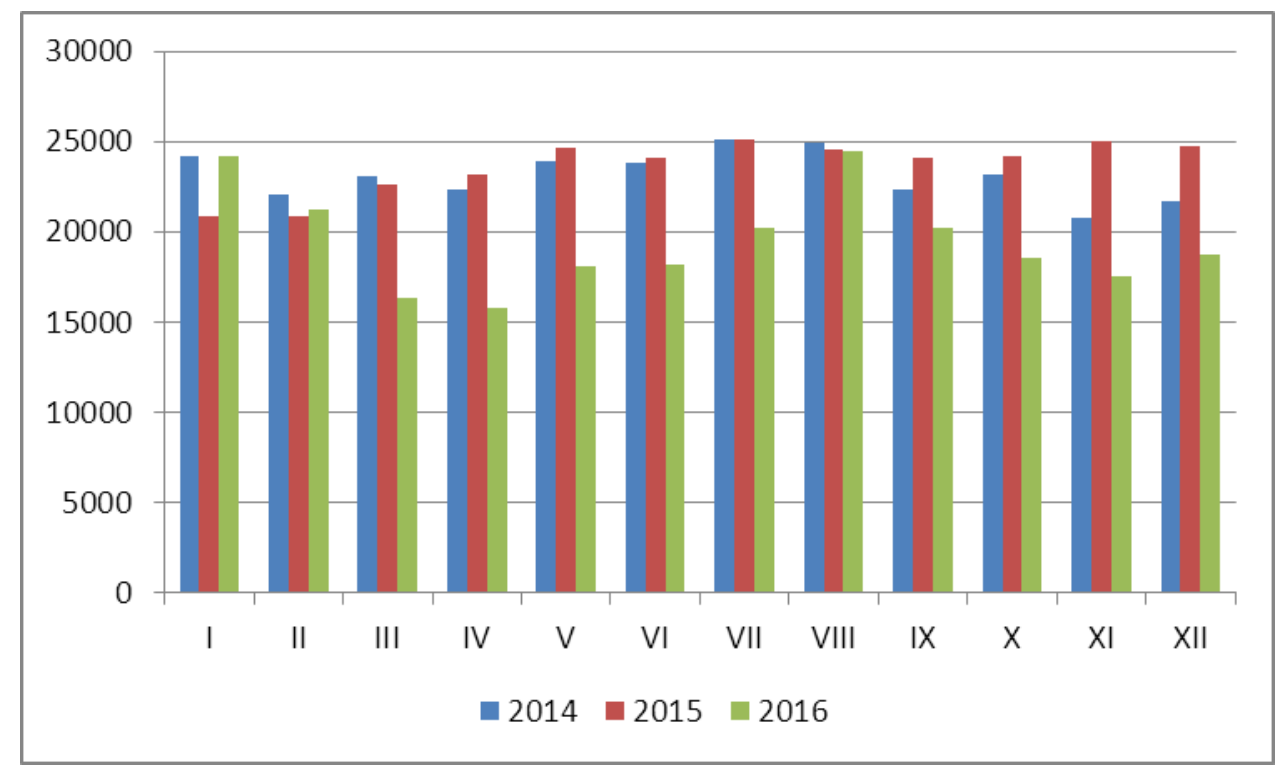

Fig. 2. Water consumption in individual months in the years 2014-2016. 
The next step was the analysis of the irregularity of water consumption over the course of a week. Figure 3 presents the results.

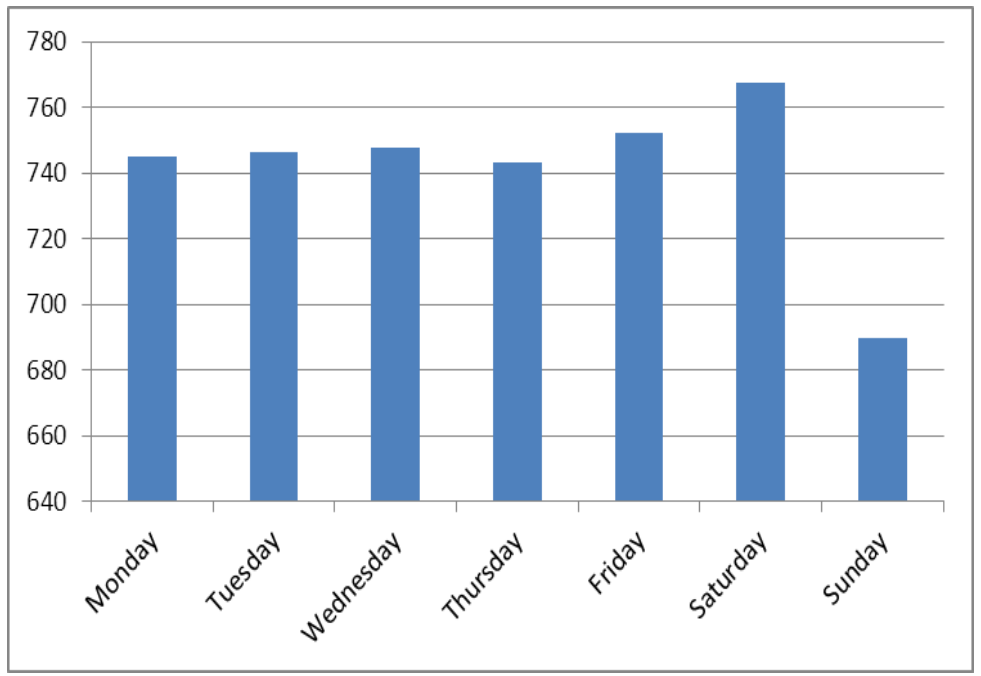

Fig. 3. Water consumption in individual days of the week.

Irregularity in water consumption during the individual days of the week can be observed. On weekdays, it is relatively even, reaching extreme values at the weekend, i.e. highest on Saturdays and lowest on Sundays. The irregularity of water consumption over the course of a week reflects the organisation of the work time and lifestyle of water recipients.

Irregularities of water consumption in the individual hours of the day were also subjected to analysis. The simulation was carried out for averaged water consumption in particular hours during years 2014-2016. Figure 4 presents the irregularity of water consumption in the form of coefficients describing pattern, necessary for carrying out calculations regarding network parameters, including water age. The values of the coefficients have been calculated from Formula (2).

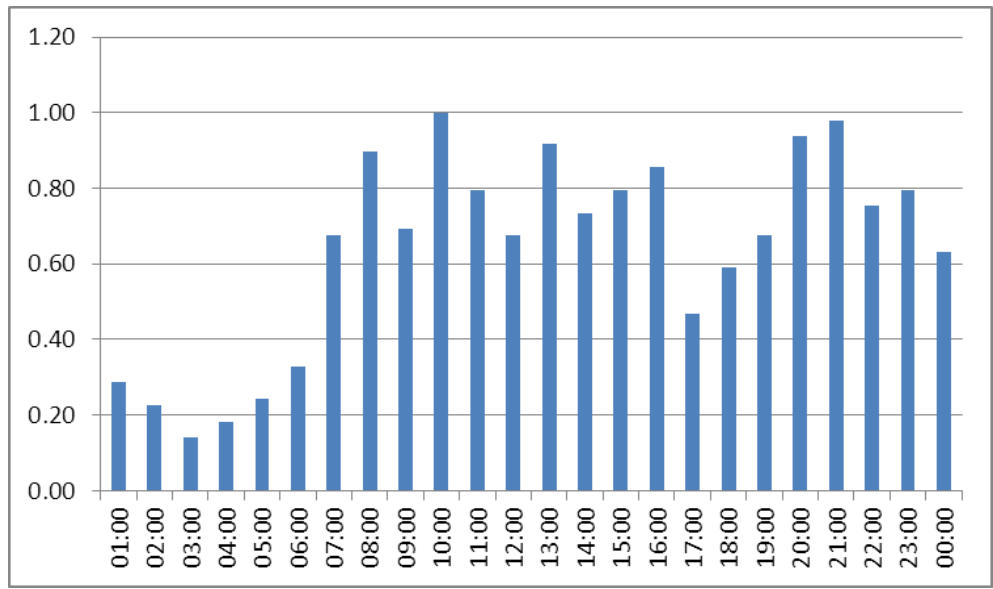

Fig. 4. Pattern of water consumption over the course of 24 hours. 
The hourly distribution is characterized by 2 peaks - before noon, at approx. 10 a.m., and evening - at 9 p.m.

\subsection{Water age}

Further calculations were carried out using the EPANET programme for the calculation scheme presented in Fig. 1. The parameter chosen for analysis was water age, reflecting flow time to the recipients. It is calculated for both the nodes as well as segments of the water supply network and forms the basis for the preliminary assessment of water quality.

Initially simulation was carried out assuming duration of 144 hours, with the obtained results of water age for individual segments falling within the range of 0.08 to 28.71 hours. In further simulation these results were taken into consideration and the applied duration was 36 hours. The highest values involve only segments of short lengths, located in the outskirts of the city. Contour lines of the water age have been presented in Fig. 5.

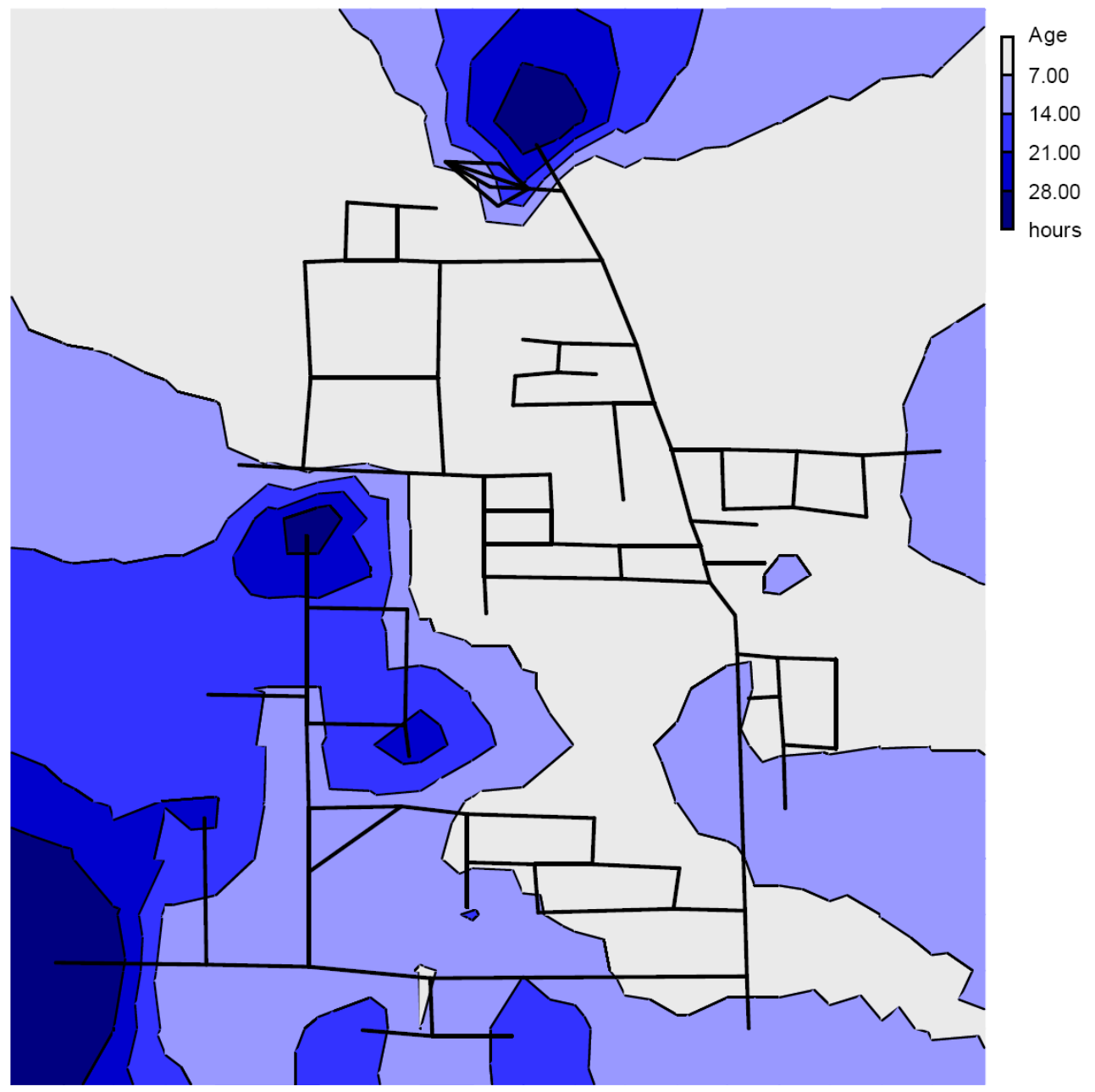

Fig. 5. Contour plot of water age.

Based on the obtained results, a cumulative graph of water age was also prepared (Fig. 6), showing in what percentage of segments a given age value occurs. 


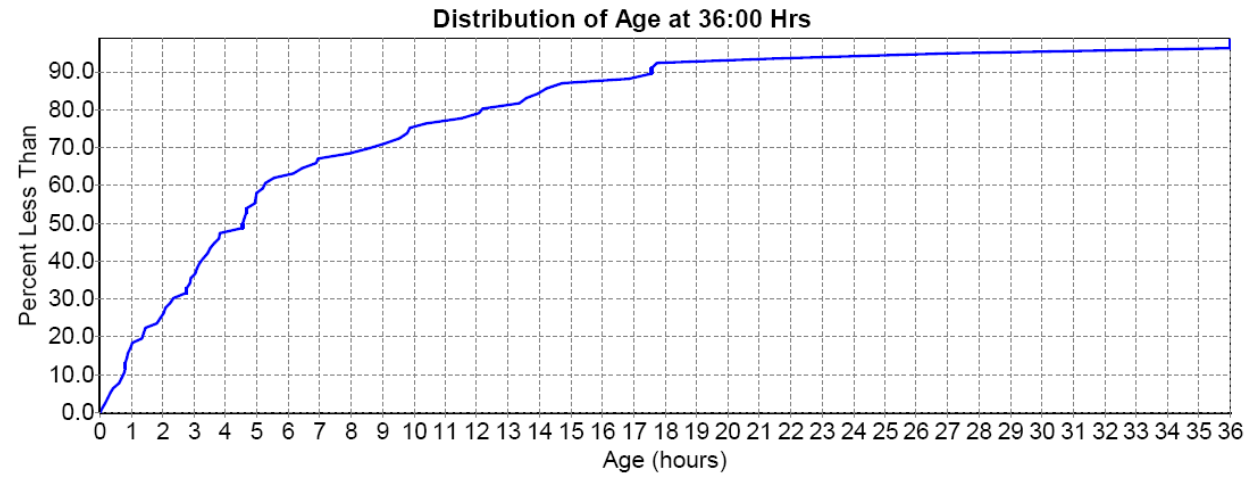

Fig. 6. Cumulative water age in Babimost water supply system.

The obtained values of water age were the basis for calculating the weighted average age of water in pipelines of a given diameter, which were carried out using Formula (3), with the results shown in Fig. 7. The obtained values fall within the range of 2.77 to 3.44 hours.

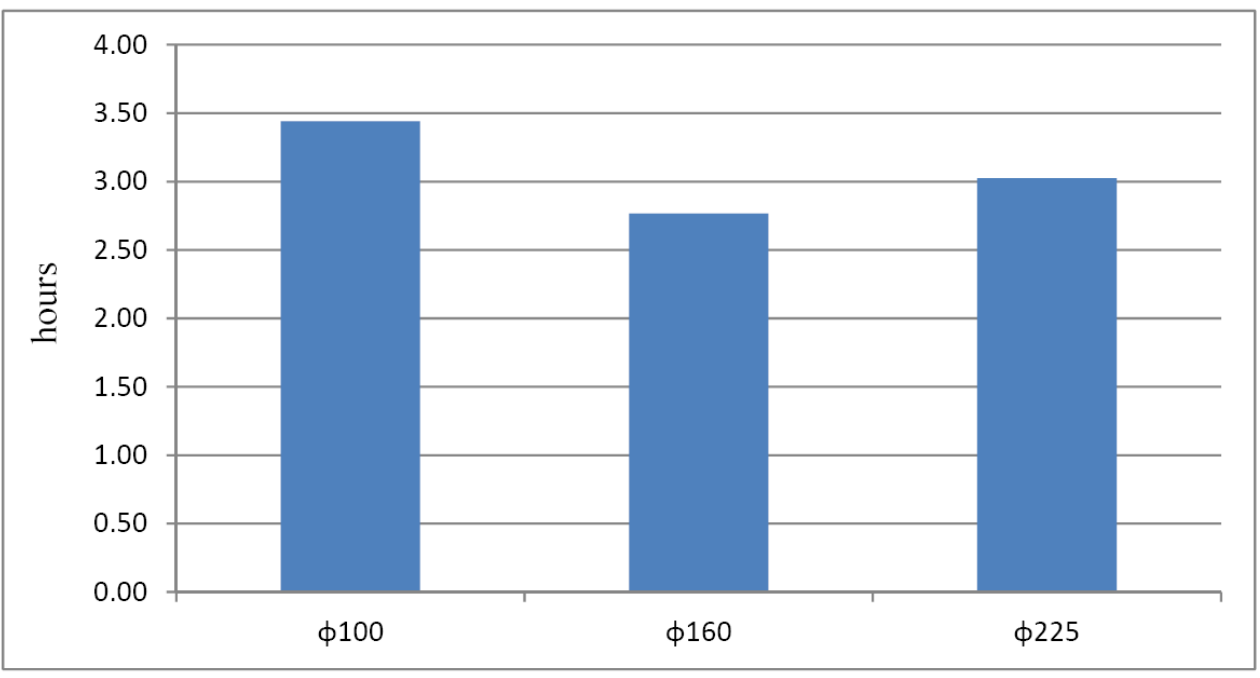

Fig. 7. Weighted average age of water in pipelines of a given diameter.

\section{Summary}

Selected parameters characterizing the water supply system in Babimost were subjected to analysis. The results pertaining to the irregularity of water consumption do not deviate from the characteristic tendencies occurring in other systems, that is a successive decrease in water consumption and its irregularity over the course of a week and day. The results of the analysis of water consumption in connection with the developed model made it possible to carry out calculations of parameters characterising the operation of the water supply system using the EPANET programme. Subjected to assessment was water age a parameter reflecting the time taken to reach the recipients, the value of which allows for 
assessing water quality. The distribution of water age is typical - the highest values occur in peripheral segments of the network.

The results of simulation showed that irregularity influences the water age. For the minimum consumption water age exceeds 88 hours, for maximum is less than 13 hours, while for water consumption irregularity over the course of 24 hours maximum water age amounts 28.71 hours.

The obtained values can be currently considered as acceptable. Decreased water consumption can, however, at some point, result in the deterioration of the analysed parameter. The major reason for this is the necessity to ensure flow to fire hydrants, which significantly diverge from typical operating conditions, even at periods of maximum water consumption. The next step of the analysis can be verification based on the periodical testing of water quality collected from end segments of the network.

\section{References}

1. M. Świderska-Bróż, M. Wolska, Ochr. Środ. 6 (2006)

2. T. Bergel, GWiTS, 3 (2013)

3. L Rossmann, EPANET 2, Users Manual (U. S. EPA, 2000)

4. E. Ogiołda, I. Nowogoński, R. Adam, SR UZ EE (to be published)

5. K. Knapik, J. Bajer, Wodociagi (WPK, 2011)

6. T. Kaźmierski, K. Mazurkiewicz, T. Schiller, JCEEA 63, 2 (2016) 